\title{
Travel as Learned Behaviour: Western migrants in Hong Kong and Macau
}

\begin{abstract}
This paper examines travel by western migrants who have moved to the Hong Kong or Macau Special Administrative Regions of China. Previous research suggests travel patterns are a form of learned behaviour. New migrants initially exhibit patterns learned from their home countries, but over time their patterns change and reflect more those of residents of their new countries as they learn and adopt new behaviours. This situation was not observed among western migrants. Instead, they exhibited patterns that were internally consistent, regardless of the migrant's origin, but different from those of the local Chinese populace. The paper argues that western migrants, who generally live in a parallel expatriate bubble to those host community, have learned travel patterns from others who also live in that bubble.
\end{abstract}

Keywords: Western professional migrants, learned behaviour, Hong Kong, Macau, travel behaviour

Acknowledgements: Funding for this project was provided for by grants from the Institute for Tourism Studies, Macau and The Hong Kong Polytechnic University.

\section{Introduction}

This study examines the travel behaviours and destination choices of Western migrants who live in the Hong Kong and Macau Special Administrative Regions of China (HKSAR, MSAR, respectively). Differences between members of this group and the host population are framed conceptually within the context of travel as learned behaviour (Harrison, Shaffer, BhaskarShrinivas 2004; Klemm, 2002). Past studies suggest that new migrants' travel patterns often reflect behaviours imported from their country of origin (Kang and Page, 2000), but over time emulate the habits of the population in the receiving country as individuals learn and adopt new 
behaviours (Feng \& Page, 2000). A number of factors that are unique to a group of Western professional migrants living in places like Macau and Hong Kong that have recent colonial pasts may mitigate against them adopting the travel norms of the host population, while residing in places far removed from their home countries may preclude them from perpetuating past behaviours. Instead, they may display unique travel behaviours that are function of membership in a diverse multi-national community that Jackson (2016) describes as functioning as a parallel expatriate bubble to that of the local population.

\section{Context}

\section{Travel as Learned Behaviour}

That travel represents a form of learned behaviour is now well recognised within the tourism literature (Fisher, 2004, 2009; Gnoth \& Matteucci, 2014; Klemm, 2002; Möller, Weiermair \& Wintersberger, 2007; Stephenson \& Hughes 2005). Fisher (2004, 2009) suggests once learned a level of inertia can set in for past actions dictate future choices regardless of whether the learning came from the individual or as a result of the adoption of patterns that reflect broader cultural and social norms. He suggests "behavior becomes reflexive as a consequence of the culture in which it occurs and the experiences gained from a particular behavior” (Fisher, 2009:37). When considered at a societal or country level, then, travel behaviour can remain remarkably constant over time (Gnoth \& Matteucci, 2014). Moller, Weiermaier \& Wintersberger (2007) add individual patterns may also change little after people reach the age of 45 , for habits are difficult to break, even if the there is an intention to do so (Light \& Young, 2014). Indeed, Butler (2015) suggests that learned travel behaviour can become so ingrained that the desire to visit certain destinations can be traced back several millennia, while the "been there, done that, brought home the t-shirt and posted on social media” behaviour common now represents a form of learned behaviour whose origins date back several hundreds of years.

Evidence of such inertia in destination choice was noted in an analysis of 10 years of outbound travel surveys of Hong Kong residents initiated by The Hong Kong Polytechnic University (Lee, 
Deniczi-Guillet, Law \& Leung, 2012). The combined sample included about 12,600 respondents, of which 99.5\% were interviewed in the local Cantonese dialect. The share of trips to non-Macau and non-China mainland destinations by distance from Hong Kong is shown for each year in Figure 1. Three features are notable. The first is the impact of distance on overall demand. Demand peaks relatively close to Hong Kong and then declines rapidly before small, secondary peaks are noted at distances coinciding with travel to long haul destinations. The decaying impact of distance on demand is a universal construct that has been found to apply to outbound travel from all economies (McKercher, Chan \& Lam, 2008). The second feature is the remarkable consistency in destination choice over time. Small variations that do occur are explained largely by differences in sample size and sampling error. Further analysis noted even smaller changes in visitation rates to specific destinations (city or resort region). Combined, these finding suggest that Hong Kong population as a whole replicates travel preferences learned over time, with little variation. The third is that the overall pattern is largely immune to change over time, in spite of the dramatic influence social media have had on tourism participation.

The lead author of the current paper acted as the principal investigator for the survey projects used in the Lee et al. (2012) study and has access to the raw data set as well as the questionnaires. What Lee et al. (2012) did not report was that a series of laddered questions was used to ascertain the total number of overnight pleasure trips taken in the previous 12 months to the Macau SAR, the adjacent Guangdong Province of China, elsewhere in China and overseas. All tolled, respondents reported just over 38,000 individual overnight pleasure trips. China was the preferred destination, accounting for almost $70 \%$ of all trips, with Macau representing another $17 \%$ of overnight pleasure trips. Collectively, then the China mainland and Macau accounted for just over $85 \%$ of all trips, while all other destinations reported by Lee et al (2012) represents fewer than $14 \%$ of all trips. The inclusion of these data accentuates both the decaying impact of distance on demand and also highlights how relatively rare travel to other, more distant destinations is. For example, while the Lee et al (2012) paper noted that $20 \%$ of non-China and non-Macau trips were taken to Japan, when all trips are considered, Japan accounts for just 1.8\% of destinations chosen. 
(Note: Both Hong Kong and Macau rejoined China in 1997 and 1998, respectively, as Special Administrative Regions (SAR) of the People's Republic of China. Both are administered under their own respective mini Constitutions that state while they are an inalienable part of China, they can be administered with a high degree of autonomy. Each is granted permission to continue to operate as separate customs territories as a legacy of their membership in the World Trade Organization prior to reintegration. As a result, each has control over customs and immigration responsibilities and a formal boundary continues to exist with the China mainland. Each can also issue separate SAR passports to all Chinese citizens who hold permanent residency. Tourists from the mainland require some type of travel permit to enter the SARs, while residents of each SAR also need some type of approved documentation to enter China or the other SAR. Foreign nationals holding require some type of visa or other special approval to enter China and, unless they are permanent residents of the SAR also require passports to enter the other SAR. Permanent residents can apply for a waiver and be allowed to enter the other SAR using their identity card. As such, both Macau and Hong Kong function as supernatural parts of China as far as tourism is concerned. To read more about the implications of the respective many constitutions on tourism close to and from China, please see McKercher and Zhang (2017)).

Insert Figure 1 About here

How do travel habits become learned and embedded? The literature points to the key roles played by reference groups (Hsu, Kang \& Lam 2006; Lin \& Chen 2009; Moutihno, 1987; Sparks, 2007). Reference groups are defined as "social groups that are important to a consumer and against which he or she makes comparisons" (Escalas and Bettman 2003:341). They can range in size from small family units and close social circles through to entire nations, if for example, societal norms including religious beliefs, linguistic, cultural and embedded behavioural values dictate behaviour (Correia, Kozak \& Ferraderia, 2011). Membership may be fixed or fluid, depending on the nature of the group and rules may be formalised or informal (Stolley, 2005). Individuals can also belong to multiple reference groups, enabling transference of ideas.

On the one hand, groups make members aware of products or services (Moutihno, 1987) and thus serve as a valuable sources of information for others in the group (Lin \& Chen, 2009). 
Individual members can simultaneously learn from the group as well as influence its future behaviour (Fisher, 2004). On the other hand, such groups provide vital cues and guidelines that ensure conformity with the group's norms by allowing members to compare themselves to the actions of other members (Escalas \& Bettman, 2003). The group, thus, may legitimise some types of behaviour through its observed collective actions (Lin and Chen, 2009), and by extension may also de-legitimise other actions.

Reference groups can be virtual or imaginary (Currie, Wesley \& Sutherland, 2008; Stolley 2005) and their influence may operate below the conscious level (Garson, 2005). People may follow behavioural patterns that are signalled as being perceived to be correct, right or cool (Radaviciene, 2015), while not being consciously aware they are doing so. Signs and signals about how to act may come from many sources, including media all types (print, electronic, social and others), a range of other markers that reflect certain values. Even the perceived popularity of an action may provide a powerful semiotic signal. The role of the travel trade, lifestyle television and newspaper articles and various lifestyle social media sites further influence behaviour. Indeed, actions can become locked in for no other reason than one group's past experiences and expectations of future experiences (Stephenson \& Hughes, 2005).

This issue is relevant to help understand the travel behaviour of migrant populations. Research conducted in western countries among migrants from Asia and Africa indicates their travel patterns deviate from those of the host community, at least in their early stages of their resettlement (Klemm, 2002; Stephenson and Hughes, 2005) but then become more similar to the host culture's travel norms over time as they assimilate more fully (Feng \& Page 2000). Reasons for observed differences include lag effect where past behaviours are repeated until new ones are learned (Kang \& Page, 2000), These findings suggest part of the migrant assimilation process then, involves joining new reference groups that influences the adoption of the travel norms of the new country. Alternately the learning process may be incomplete among those whose planned stays are short (Hughes and Allen, 2010), or for people who have difficulty adjusting to the new life (Selmer \& Leung 2007; Zimmermann, Holman \& Sparrow, 2003). Here, it is suggested they may either retain their old travel patterns or patterns may be influenced by others temporary residents who have little interest in assimilating fully. 


\section{Western Professional Migrants and the Postcolonial Legacy of 'White Privilege'.}

The Western community in post-colonial Asia represents a unique group of migrants. It has been described as existing in a parallel expatriate bubble that is largely isolated from the local population, in which residents "practice their daily lives through routinized actions that are different from the routines of the local population” (Jackson 2016: 297). The presence of such a bubble is thought to exist even among long term Westerners who define themselves as 'locals' and who disassociate themselves from newer expatriates, for, as Leonard (2008) asserts they can never fully let go of their identities. The reasons are manifold, but one of the underlying driving forces seems to be an ongoing legacy of white privilege that engenders an enduring sense of superiority. While Leonard (2008) wrote about this issue nearly 10 years ago, white privilege continues today as a number of journalists have commented on it and its impact on the local community (Lhatoo 2016, Yip 2017). A degree of inertia seems to have set in, whereby even though the population of former colonials has shrunk and been replaced by a much more diverse community of westerners, its existence continues to inform attitudes and behaviours. One reason is that many of the social institutions frequented by westerners remain, including a separate schools ranging from the English Schools Foundation to national private schools, such as the Australian International School, social clubs and sporting organisations. Plus, westerners still tend to reside in selective neighbourhoods, with various websites such as www.Asiaexpat.com, www.justlanded.com, https://expatliving.hk, https://hongkong.xpat.life, and even organisations like the English Schools Foundation advising new residents about preferred locales.

Their lives are something akin to the Two Solitudes defined in the quintessential Canadian novel of the same name written by Hugh MacLennan. This novel discussed the fraught relationship between English Protestants and French Catholics in Montreal. While each lived in the same physical space, they existed in quite discrete social and economic worlds (Bevalas, 2005). As in 
the novel, Hong Kong and Macau's two solitudes is signed and signalled both overtly as well as subtly by the actions of members of each group.

The Western community in both places is numerically small, but socially and economically privileged (HSBC, 2016). It is also ethnically diverse, as reflected by the fact the survey used in this study captured over 50 different non-Asian nationalities. According to the Hong Kong Census and Statistics Department's Thematic Report on Ethnic Minorities (CSD, 2012) about 55,000 people or $0.8 \%$ of the population were identified as 'White' in the most recent census (CSD, 2012). White here is a formal ethnic classification used by the Census and Statistics Department to denote Caucasian residents of European, North American and Oceanian descent (CSD, 2012). It is interesting to note that such racial profiling began only after the handover of Hong Kong to China. Their median age was 38 and two-thirds were married. Three-quarters are university graduates. Less precise figures are available for Macau, although likely fewer than 10,000 'white’ people live here (DSEC, 2012), constituting less than two percent of the population. The Hong Kong census report (CSD, 2012) notes further that 'White' men in the workforce report a median annual income of more than US\$90,000, while 'White' women who were working reported a median annual income of about US\$50,000. These figures compare favourably to the overall median household income of US\$17,000. In fact, the real income disparity may be higher, for one study of expatriates reported median household incomes of US\$170,000 per annum (HSBC, 2016). Many also have generous housing, schooling and paid vacation allowances which sometimes include flights back to one’s home country.

Westerners tend to cluster in certain neighbourhoods or housing estates, where they represent a disproportionately large minority of the population. They tend to shop and dine in establishments where staff speak English. Expatriate associations, sporting organisations and social clubs play a key role in forming social networks, and provide a respite from the local community, where people can mingle with other Westerners (Leonard, 2008; Shaw, 2006). Moreover, most Westerners send their children to international schools (Hugo, 2006; Tanner 2007), and sign them up for sporting activities, such a rugby and netball, that are popular among expatriates but mush less so among the local Chinese population. School, clubs and sporting groups help create 
new social networks which eases adjustment, while also reinforcing the otherness of this group from the mainstream population.

The fact that many are transient complicates the matter further for the population consists almost entirely of first generation migrants (Leonard, 2008). Indeed, the level of instability and turnover in the migrant population is one of the few constants that defines this group. This very instability may, in fact, serve to embed existing behaviours as the norm, for people rely on learned behaviours of other transients before them, but rarely stay long enough themselves to learn new behaviours or to alter the existing status quo (Harvey, 2008). Directed migrants, those who are posted by overseas companies, stay between one to five years (Harrison et al., 2004). Because they see their stays as short term posting, few try to assimilate into the broader Chinese community and instead associate with other short stayers who belong to the types of organisations mentioned above. Many self-directed migrants (Inkson \& Myers, 2003; Richardson \& Mallon, 2005; Richardson, 2006) who move overseas on their own volition also plan short stays especially if an overseas work experience represents a symbolic rite of passage into adulthood (Australian Senate, 2005; Inkson \& Myers, 2003; Williams \& Hall, 2002) or change after undergoing life altering events such as a marriage breakdown (Richardson \& Mallon, 2005; Roderick, 2011; Thorn 2009). The authors have observed, for example, that some schools catering for migrants have an annual turnover of up to $25 \%$ of the student population in certain grades. Alternately, some who arrive with the intention of staying for only short periods of time, end up staying longer (Inkson \& Myers, 2003), while many long-term residents have firm departure plans (Banai \& Harry, 2005; Khoo, Hugo \& McDonald, 2008).

Language, or more accurately, language deficiencies, arguably represent the key reason for the continued existence of the two solitudes-like expatriate bubble. Few Westerners are interested in or willing to learn Cantonese (Amaro, 2016; Lei, Udani \& Arches, 2011; Yee 2001). Instead, English has become the common default language regardless of the migrants' original linguistic background (Young, 2007). Its use is so prevalent that it has been described as a bond that unites Westerners (Wang \& Kanungo, 2004). Reliance on English is a double-edged sword, for on the one hand it effectively precludes most Westerners from integrating fully into the local 
community (Amaro, 2015), and, ironically, on the other hand provides a powerful excuse not to do so (Amaro 2016; Choe \& O’Regan, nd).

Leonard (2008) argues the main reason why most Westerners are reluctant to learn Cantonese has more to do with an enduring sense of white privilege and an attitude of white superiority that traces its roots to Hong Kong and Macau's colonial past. She is blunt when asserting "Hong Kong's history as a British colony means that whiteness is (still) located as a badge of race privilege and structured advantage” (Leonard 2008: 47). Wang, Wong \& Zheng (2014) and Amaro (2016) examined expatriates in each locale, and came to similar conclusions. Amaro (2015:42) observed for example, Portuguese in Macau "have always understood and experienced Macau as a Portuguese colony, and this has engendered a durable sense of superiority that is reflected in their practices towards members of the same group (the Portuguese community), the Other, and the position they hold in the field."

This attitude has proven remarkably resilient to change (Subedi \& Daza 2008) for it perpetuated by both Westerners and local Chinese alike. Harrison, Shaffer \& Bhaskar-Shrinivas (2004) remind us that many Westerners who move to Asia bring a prevailing repertoire of perceptions, interpretations, and behaviours from their native culture that engenders a mistaken perception that these norms and attitudes are superior to those of the receiving country. Even long stay expatriates who see themselves as locals never fully relinquish established notions of whiteness, Britishness and privilege (Leonard, 2010). Chiu, Wu, Zhuang and Hsu (2009) and Lan (2011) note quite a complex and contradictory attitude among many Chinese people. On the one hand, Westerners are tolerated, but not embraced, but on the other hand 'Whiteness' as is a highly sought, but heavily racialized commodity (Lan, 2011), where host country subordinates may be motivated to mimic behaviours of their expatriate managers.

While a deeper discussion of 'white' privilege is beyond the scope of this study, it, along with language barriers, the prevalence of a well-structured, but parallel school, sporting and social club scene and residential clustering in certain neighbourhoods reinforce why Westerners and locals live different lives. It also highlights how each relies on different direct and indirect reference groups to inform behaviour. Clearly, the school, club and sporting culture creates its 
own direct social groups where interaction influences a range of behaviours from where to shop and eat to what type of trip to take. But the lack of written and oral Chinese language skills effectively excludes them from being informed by the local media, social network sites and even the local travel trade that in a sense creates virtual or imagined reference groups.

Thus, while being a Westerner in Hong Kong or Macau certainly has a number of advantages, it may also embed a degree imposed and self-imposed social and racial ghettoism that embeds the sense of otherness. Choe and O'Regan (nd) found that skilled expatriates in Macau liked the economic and lifestyle opportunities provided there but admitted they did not feel accepted by the community. Leonard $(2008,2010)$ commented on how difficult it was for British expats to negotiate the racially infused 'us' and 'them' on Hong Kong society. This isolation is not unique to places like Hong Kong and Macau, and may even be more profound in countries with even smaller expatriate populations. Lan (2011:1688), for example, notes that the cultural backgrounds of Westerners in Taiwan places them simultaneously in a privileged, yet imposed segregated social environment of being a “the English person”.

As a result, westerners are othered, either by choice, default in the instance of reluctance to learn a new language, or as a function of attitudes of the dominant local Chinese community. The otherness is aided and abetted by a wide variety of social media that reinforce both their outsidedness from the host community and insidedness as members of the expatriate community. Such group membership invariably influences all forms behaviour from where to live, shop, dine to where to school children and what social networks to form. It should also inform travel behaviour.

\section{Method and respondent profile}

A non-random, purposive sampling technique was adopted for this study. The target audience was 'white' residents as defined by the Hong Kong Census and Statistics Department who have lived in either the Hong Kong or Macau SAR for a minimum of one year. Two rounds of data 
collection were undertaken in each locale. The first round involved an on-line survey operating from January through October, 2016 targeting members of expatriate clubs, other organisations with a large Western population and the study teams' professional contacts. The second round of operated from January to October, 2016 in Macau and from November through December, 2016 in Hong Kong and involved direct contact with potential participants. In Macau, for example, student helpers distributed surveys to members of social clubs, sporting clubs and educational institutions and also sought permission to distribute the survey to individuals who patronised cafes and pubs frequented by Western expats. In Hong Kong, a team of student helpers was employed to approach people directly in neighbourhoods with a large western population as well as at locales where Westerners congregated, such as ferry piers, popular dining locations and at sporting event. In all cases, respondents were vetted to ensure they met the residency criterion before they were given a self-response survey with a stamped-return envelope. The cohorts of on-line and off line participants were then compared and found to be internally consistent, enabling merging of the data.

The survey instrument consisted of four parts. The first part gathered details on the respondents' migration history, sense of attachment to Hong Kong or Macau and the role the opportunity to travel played in the migration decision. An open-ended question determined respondents’ countries of origin by asking them "when people ask where do you come from, which country or countries do you mention?” The second section focussed on their pleasure travel behaviour patterns and asked participants to provide information on annual leave allowances, the importance of travel, and to list all main destinations for any long (2 weeks or longer), medium (six to 13 nights) and short duration (between one and six night) trips taken in the past year. Follow-up questions asked if their travel behaviour had changed since they moved to the region. The third and fourth parts sought information on the demographic profile of respondents, including children. Data cleaning yielded a viable sample of 1232 cases, including 690 from Macau and 542 from Hong Kong. All statistical procedures were performed using SPSS 24. Descriptive statistics were derived for all socio-demographic variables. Additionally, Pearson Chi-square test and one-way analyses of variances (ANOVA) with an alpha value of 0.05 were performed to explore for potential differences between variables of interest. p-values less than 0.05 were considered significant. 
As with any study, some caveats must be recognised. The first is that the sample was nonrandom, and as such, may not reflect fully the views of the Western migrant community. However, the approach adopted represented a practical means to access as diverse a group of Westerners as possible. The costs of conducting a truly randomised sample would have been prohibitive given the small population of Westerners in each location. Second data were collected from membership based organisations and locales with large western populations. As such, residents who either did not belong to such groups or who lived elsewhere were excluded from the study. Finally, the sampling procedure of targeting clubs, associations and sporting groups may exacerbate the impact of reference groups on the learning processes.

\section{Profile of Respondents}

Demographic information was provided by 1221 respondents and is summarised in Table 1. Overall, their profile corresponds closely to available census data. British nationals (38\%) represented the largest share of respondents from Hong Kong, and Portuguese nationals (21\%) represented the largest group of Macau respondents. Overall, about 19\% identified Western European countries other than the UK and Portugal as home, 17\% Australia or New Zealand, 15\% USA and eight percent Canada. Interestingly, some 19\% also said they came from Hong Kong or Macau, with three percent stating it as their only country or origin, even though they had migrated here from other places. The median age for all respondents was between 35 and 44 . About three quarters were partnered and over half of those who are partnered had children. Just under half of partnered respondents (46.3\%) stated their partners came from countries that were different to their own, with about four in ten from other European countries, one-third from Asia, about 10 percent each from North America or Oceania. The median household income was between US\$130,000 and \$260,000. About one-quarter earned between US\$65,000 and US\$130,000, while another quarter were very high-income earners, with household incomes in excess of US\$260,000 per annum. They also enjoyed long vacation entitlements of between four and five weeks per annum. Most (70.3\%) said Hong Kong or Macau felt somewhat or definitely like home, while only five percent said it definitely did not. 
Somewhat unexpectedly, only about one in five was posted by an overseas company. Instead, just over half were self-initiated migrants. About one quarter identified themselves as trailing spouses, with women constituting $71 \%$ of this group. The median length of residence in the region was eight years, with one quarter being relatively new residents (here for less than three years) and just under one-third long stay residents who had been in the region for more than 15 years. About one-quarter intended to leave within three years. Most, though, stated their stay was open-ended, although one must interpret this response with caution for opened-ended does not necessarily equate with a permanent stay.

The literature suggests the opportunity to travel can play an important role in the migration decision for self-directed migrants and is an important, but secondary reason why many directed migrants take an overseas posting (Butler \& Richardson, 2013, Richardson \& Mallon, 2005; Roderick, 2011; Thorn, 2009). That situation is apparent here for three-quarters indicated the chance to travel to or in this region played some role in their decision to move, with one in five saying it was the most important reason why they moved.

\section{Travel Patterns}

The following section discusses the respondents' travel behaviour. The discussion begins with a brief summary of their overall travel propensity and intensity followed by a comparison of their destination choice to that of the background rate of Hong Kong residents.

\section{Travel propensity and intensity}

Table 2 summarizes overall travel propensity and intensity of the sample population. Almost all Western professional migrants (91.5\%), took at least one overnight pleasure trip outside of their own SAR in the past year. This figure compares favourably to the background propensity rate for 
Hong Kong as a whole of between two-thirds and three-quarters of the population, depending on the state of the economy (McKercher, 2009).

On average, respondents took a mean of 3.4 overnight pleasure trips per annum. The number ranged from a low of one trip, recorded by $20 \%$ of respondents, to 10 or more pleasure trips registered by one percent. Interestingly, the mean number of trips is comparable to the background rate for Hong Kong and Macau residents as a whole (McKercher \& du Cros, 2008), however, destination choice varied dramatically, as discussed later. Intensity levels or the number of trips taken were related to the importance of travel in the migration decision ( $F=$ 198.802, $p<.001)$ and income level $(F=192.020, p<.001)$. Those who stated travel was an important reason to migrate took an average of $50 \%$ more trips a year than those who said it played no role (4.1 vs. 2.8), with the greatest difference noted in frequency of visiting Asian destinations (3.2 vs 2.0). High income earners took an average of 1.6 more trips per annum than the lowest income cohort (4.4 vs 2.8). The likelihood of travelling to long haul, non-Asian destinations $\left(\chi^{2}=34.085, p<.001\right)$ and engaging in trips lasting more than two weeks $\left(\chi^{2}=\right.$ 28.892, $p<.001$ ), were also tied closely to income. Here, just over half (53\%) of those in the lowest income category (earning less than US $\$ 65,000$ ) travelled long haul, compared to twothirds of members of the middle three income categories (earning between US\$65,000 and US\$390,000) and $88 \%$ of the highest income earners (earning in excess of US\$390,000). In a similar manner, less than half of the lowest income earners took trips of two weeks or more, compared to about $58 \%$ of those earning between US $\$ 130,000$ and US $\$ 390,000$ and $84 \%$ of the highest income group.

Insert Table 2 about here

\section{Destination choice}

The most effective method to compare travel behaviour of Western migrants with the local population is to analyze the share of arrivals at each destination, with destinations ordered by distance from Hong Kong. In this manner the decaying impact of distance on demand, if any, could be noted. Figure 2 compares the migrants' destination share to that of Hong Kong residents. 
The green line shows the demand curve for outbound travel from Hong Kong as determined by UN World Tourism Organization statistics from 2015. (Note, no such detailed figures are reported for Macau, but as McKercher \& du Cros (2008) determined the patterns are similar.) Gaps in this line are a function of the fact that some destinations do not record arrivals from Hong Kong as a discrete source market. The blue shows the share of total trips recorded by the sample as a whole, while the purple line shows share of arrivals with home return travel excluded. The overall pattern for Hong Kong residents reflects a fairly normal distance decay pattern, and as Lee et al. (2012) found, is stable over time. Demand peaks at the most proximate destination of the China mainland and the respective fellow SAR, before declining sharply as distance increases until the effective tourism exclusion zone defined by large swathes of ocean and many Middle Eastern countries is crossed. Small secondary long-haul peaks are noted, but in all cases, they represent less than two percent of outbound volume.

Insert Figure 2 about here

By contrast, the China mainland holds relatively little appeal for migrants, generating less than nine percent of all overnight pleasure trips, compared to more than $86 \%$ for Hong Kong residents. Likewise, Taiwan and sister SARs of Macau or Hong Kong are also relatively unappealing as overnight destinations. Instead, Thailand emerged as the single most popular destination, with strong demand also noted from such Asian destinations as Japan, Vietnam, Singapore and the Philippines. Long haul destinations of the UK and the USA rounded out the top 10 destinations for this market.

The literature suggests migrants' travel behaviour patterns can be distorted by the powerful role home return travel plays for many migrants (Ali \& Holden, 2006; Reynolds, 2010: Tanner, 2007). To control for this possible effect, share values were recalculated with home return travel removed. They are shown in the purple line. Home return travel has only a modest impact on the overall destination choice, accounting for only a small increase in short haul demand and only a small decline in high long-haul demand is observed. The reason is that home return travel is not 
particularly popular among this migrant cohort. Less than $10 \%$ of all trips taken and only $29 \%$ of the more than 1,220 long haul trips recorded involved a home return component.

The literature also suggests that destination preference as learned behavior may be country (Thane and Farstad 2012) or ethnic specific (Klemm 2002). If so, migrants from different regions should exhibit different travel patterns. Alternately, if the local western migrant community can be considered as a somewhat homogeneous group, whose behaviors transcend national and ethnic boundaries and instead reflect collective learned behavior of living in a parallel expatriate bubble, then few differences should be noted regardless of where they originated. This proposition is tested in Figure 3, where separate share lines are calculated for people who come from five major regions of Portugal, the UK, Western Europe, North America (Canada and the USA) and Oceania (Australia and New Zealand). For ease of interpretation, travel to home countries has been deleted, as such visitation spikes are noted for each group.

Destination choice, especially within Asian destinations, is largely internally consistent, regardless origin. Greater China holds little appeal, compared to Southeast and North Asian destinations. Some small differences were noted in short haul destination preferences, but in all cases, they do not distort overall patterns significantly. For example, Portuguese respondents, who exclusively reside in Macau have a greater tendency to visit Hong Kong; members of the three European groups show more interest in the Philippines than Australians or North Americans, while Western European are somewhat less likely to visit Vietnam; and somewhat more interested in Japan. Differences noted in long haul destination choice may correspond partially to behavior imported from the migrants' country of origin. But again, the impact is modified heavily here, for many migrants took advantage of residing in this region as a chance to travel to other long-haul destinations that would be difficult to reach from their home countries. About one third of long haul travel by North American and Oceania migrants involved trips to Europe, while one-quarter of British and Oceania migrants visited the Americas. In a similar manner, about $15 \%$ of migrants from North America and Europe took the opportunity to visit Australia or New Zealand.

Insert Figure 3 about here 


\section{Discussion and Conclusions}

This study represents the first of its kind to examine travel by Western professional migrants who have moved to Asian cities. This group of individuals represents a unique sub-population that lives in a parallel world to the dominant host population. Trade publications label them as 'privileged' (HSBC, 2016) because of their high incomes, preferential employment packages and, as identified in this study, long vacation leave allocations. 'Advantaged' may be a more apt descriptor as far a pleasure travel is concerned, for the combination of the factors obviates the types of time, income and cultural distance constraints that influence by the local Chinese populations, making their behaviours adhere more rigorously to the distance decay concept. The importance of the opportunity to travel in the migration decision is an understudied phenomenon. Yet, three quarters of respondents said it played some or an important role in the decision to move. Those who said it played a role were far more active than others, especially in Asia.

Notably, consistent patterns are observed in destination choice, especially within Asia, regardless of the origin of the migrant, and these patterns are quite distinct from those of the host population. Little evidence exists to suggest these patterns mimic those of residents of their home country, other than perhaps some long-haul destination choice. Almost no evidence exists to suggest that this group has adopted the behaviours of the host Hong Kong or Macau populations. Instead, they have developed their own unique patterns that reflect a form of new, collectively learned behaviour. The commonality in destination choice suggests something more is at play than simply affluence. Instead it suggests collective learning transcends national backgrounds. The findings suggest it is influenced by membership in exclusive transnational reference group or set of groups, that are defined as much by their insidedness as Caucasian, English speakers living in an expatriate bubble as by their outsidedness from the host population. Interestingly, while a large majority say Hong Kong and Macau feel like home, what constitutes home to them seems to be quite different than how a native resident would describe home. It seems that they feel at 'home' in the expatriate community. Even though membership is fluid, this community still seems to retain sufficient cohesion to influence behavioural norms, including travel. 
These traits may prove advantageous for travel to culturally similar, Western long haul destinations, as well as to culturally dissimilar non-Chinese Asian destinations. Ironically, though, the very same traits become liabilities when considering travel to and within greater China (China, the two SARs and Taiwan). While these places are appealing to local residents as low cost, linguistically and culturally similar destinations, the migrants' linguistic and cultural isolation from the host population renders them less appealing, especially if they see travel as an escape from an oppressive local culture (Zimmermann, Holman \& Sparrow, 2003). Greer and Wall (1979: 230) commented that people need to travel a certain distance or else they do not feel "sufficiently removed from their accustomed environment to regard themselves as taking a pleasure trip.” For many migrants, it is evident that the prospect of travel to Greater China does not signify sufficient removal from the accustomed environment to evince a sense of escape.

It is also worth noting that, historically, the global professional expatriate community was comprised almost exclusively of westerners who move to non-western countries. However, the rise of Asian economies and the emerging globalisation of many businesses here is producing a reverse professional migrant flow where similarly educationally, culturally and skilled privileged migrants from Asia are moving to western countries, often on short term contracts (Mayberry, 2017). It would be interesting to see if the travel behaviour shown by Western migrants are replicated by similar Asian migrants. Because the Westerners in Hong Kong and Macau appear to exhibit travel behaviour different from those reported in the literature, it may be worthwhile to extend this investigation to Western expatriates living in Western industrialized economies. Sufficient has been said to indicate the need for research investigating Western expat travel patterns outside the rubrics of second home ownership and lifestyle migration. This is an issue as a wealth of empirical research (e.g. Beaverstock 2005; Ryan, 2007; van Riemsdijk \& Wang, 2017) indicate that Western expats in western societies see themselves as differentiated and separate asserting their class position in corporeal travel. 


\section{References}

Ali, N., \& A. Holden 2006). Post-colonial Pakistani mobilities: The embodiment of the 'myth of return’ in Tourism. Mobilities, 1(2): 217 - 242.

Amaro, V. (2015) “We”, “They” and the spaces in-between: Hybridity in intercultural interactions between Portuguese and Chinese residents in Macau. Multilingua: Journal of Cross-Cultural and Interlanguage Communication, 34(3): 293-318.

Amaro, V (2016) Linguistic practice, power and imagined worlds: The case of the Portuguese in postcolonial Macau. Journal of Intercultural Studies, 37(1): 33-50

Australian Senate (2005), They Still Call Australia Home: Inquiry into Australian Expatriates, Commonwealth of Australia, Canberra. Retrieved September 3, 2012 from http://australiaitalia.it/Pdf/Australian\%20Expatr\%20Const\%20Ref.pdf

Banai, M., Harry, W. (2005), Boundaryless global careers, International Studies of Management and Organisation, 34(3): 96-120.

Beaverstock, J.V. (2005) Transnational elites in the city: British highly-skilled inter-company transferees in New York city's financial district. Journal of Ethnic and Migration Studies, 31(2): $245-268$

Bevalas, J. (2005) The Two Solitudes: Reconciling social psychology and language and social interaction. In Fitch, K and Sanders, R. (Eds.) Handbook of Language and Social Interaction (pp. 170-200). London: Lawrence Aerlbaum Associates.

Butler, G., \& S. Richardson (2013) Working to travel and long term career dilemmas: Experiences of Western lifestyle migrants in Malaysia. Tourist Studies, 13(3): 251-267.

Butler, R. (2015) The evolution of tourism and tourism research. Tourism Recreation Research, 40(1): 16-27.

Chiu, Y., Wu, M., Zhuang, M. \& Hsu, Y. (2009) Influences on expatriate social networks in China. The International Journal of Human Resource Management, 20(4):790-809

Choe, J., \& O’Regan. M. (nd) The Effects of Tourism Impacts Upon Quality of Life Amongst Expatriates in Macau. Retrieved August 4, 2017 from http://eprints.bournemouth.ac.uk/22915/1/Choe-and-Oregan.pdf

Correia, A., Kozak, M., \& Ferraderia, J. (2011). Impact of culture on tourist decision-making styles. International Journal of Tourism Research, 15(3): 433-446. 
CSD (2012) Thematic Report : Ethnic Minorities. Hong Kong: Statistics and Census Department.

Currie, R., Wesley, F., \& Sutherland, P. (2008) Going where the Joneses go: understanding how others influence travel decision-making. International Journal of Culture, Tourism and Hospitality Research, 2(1): 12-24,

DSEC (2012). Results of 2011 Population Census. Macau: Department of Census and Statistics

Escalas, E. J, \& Bettman, J. R. (2003) You are what they eat: The influence of reference groups on consumers’ connections to brands. Journal of Consumer Psychology, 13(3): 339-348.

Feng, K., \& S. Page (2000) An exploratory study of the tourism, migration-immigration nexus: Travel experiences of Chinese residents in New Zealand. Current Issues in Tourism, 3(3): 246-281.

Fisher, D. (2004) The demonstration effect revisited. Annals of Tourism Research, 31(2): 428446.

Fisher, D. (2009) Grid-group analysis and tourism: tipping as a cultural behavior. Journal of Tourism and Cultural Change, 7(1): 34-47

Fitzgerald, C., \& L. Howe-Walsh (2008) Self-initiated expatriates: An interpretative phenomenological analysis of professional female expatriates. International Journal of Business Management, 3(10): 156-175

Garson, B. (2005) Teaching abroad: A cross-cultural journey. Journal of Education for Business, 80(6): 322-326.

Gnoth, J., \& Matteucci, X. (2014) A phenomenological view of the behavioural tourism research literature. International Journal of Culture, Tourism and Hospitality Research, 8(1): 3-21

Greer, T., \&. Wall, G. (1979). Recreational hinterlands: A theoretical and empirical analysis. In G. Wall (Ed.), Recreational land use in Southern Ontario (pp. 227-46). Department of Geography Publication Series No. 14. Waterloo, Canada: Waterloo University.

Harrison, A., Shaffer, M., \& Bhaskar-Shrinivas, P. (2004) Going places: roads more and less traveled in research on expatriate experiences. Research in Personnel and Human Resources Management, 23: 199-247

Harvey, W., (2008) The social networks of British and Indian expatriate scientists in Boston. Geoforum 39: 1756-1765.

HSBC (2016) Expat Explorer: Achieving ambitions abroad. HSBC Banking Corporation. Retrieved on March, 6, 2017 from 
https://www.expatexplorer.hsbc.com/survey/files/pdfs/overallreports/2016/HSBC_Expat_Explorer_2016_report.pdf

Hsu, C., Kang, S., \& Lam, T. (2006) Reference group influences among Chinese travelers. Journal of Travel Research, 44: 474-484.

Hughes, H., \& D. Allen (2010) Holidays of the Irish diaspora: The pull of the 'homeland'? Current Issues in Tourism 13(1): 1- 19.

Hugo, G. (2006) Developed country diasporas: The example of Australian Expatriates. Espace, Populations, Societies, 1: 181-202.

Inkson, K., \& B. Myers (2003) “The Big OE”: self-directed travel and career development. Career Development International, 8(4): 170-181

Jackson, L (2016) Experiencing exclusion and reacting to stereotypes? Navigating borders of the migrant body. Area, 48(3): 292-299

Kang, S., \& S. Page (2000) Tourism, migration and immigration: travel patterns of Korean -New Zealanders in the 1990s. Tourism Geographies, 2(1): 50-65

Khoo, S., Hugo, G. \& P. McDonald (2008) Which skilled temporary migrants become permanent residents and why? International Migration Review, 42(4): 193-226.

Klemm, M. (2002) Tourism and ethnic minorities in Bradford: The invisible segment. Journal of Travel Research, 41: 85 - 91.

Lan, P. (2011) White privilege, language capital and cultural ghettoisation: western high-skilled migrants in Taiwan. Journal of Ethnic and Migration Studies, 37(10): 1669-1693

Lee, H., Deniczi-Guillet, B. D., Law, R. \& Leung, R. (2012), Robustness of distance decay for international pleasure 21ehaviour21: A longitudinal approach. International Journal of Tourism Research, 14: 409-420.

Lei, W., Udani, Z \& Arches, A. (2011) Social adjustment of expatriates in Macau: Evidence from the gaming industry. Euro Asia Journal of Management, 21(40): 3-23.

Leonard, P (2008) Migrating identities: gender, whiteness and Britishness in post-colonial Hong Kong. Gender, Place \& Culture, 15(1):45-60

Leonard, P. (2010) Organizing Whiteness: Gender, nationality and subjectivity in postcolonial Hong Kong. Gender, Work and Organization, 17(3): 341-358.

Lhatoo, Y. (2016) White worship in Hong Kong: you can't end it if you refuse to acknowledge it even exists. South China Morning Post Feb 3, 2016. 


\section{http://www.scmp.com/comment/insight-opinion/article/1873833/white-worship-hong-}

kong-you-cant-end-it-if-you-refuse < downloaded, Nov 23, 2017>.

Light, D., \& Young, C. (2014). Habit, memory, and the persistence of socialist-era street names in post socialist Bucharest, Romania. Annals of the Association of American Geographers, 10(3): 668-685.

Lin, L., \& Chen, Y. (2009) A study on the influence of purchase intentions on repurchase decisions: the moderating effects of reference groups and perceived risks. Tourism Review, 64(3): 28-48

Mayberry, K (20017) The rise of the Asian expatriate. BBC. Retrieved March 7, 2017 from http://www.bbc.com/capital/story/20170203-the-rise-of-the-asian-expat

McKercher \& H. du Cros (2008): A comparison of international travel between an emerging and a mature source market. Asia Pacific Journal of Tourism Research, 13(3): 265-280

McKercher B (2009) Non-travel by Hong Kong residents. International Journal of Tourism Research, 11(6): 507 - 519.

McKercher B., Chan A \& C Lam (2008) The impact of distance on international tourist movements. Journal of Travel Research, 47 (2): 208-224.

McKercher, B., and R Zhang (2017 Hong Kong as a Supranational Destination for Chinese Tourists. China Tourism Research. DOI: 10.1080/19388160.2017.1350613

Möller, C., Weiermair, K., \& Wintersberger, E. (2007) The changing travel behaviour of Austria's ageing population and its impact on tourism. Tourism Review, 62(4): 15-20

Moutihno, L. (1987) Consumer Behaviour in Tourism. European Journal of Marketing, 21(10): $5-44$.

Radaviciene, I. (2015) Consumer behaviour and psychology. Vilnius: SMK University of Applied Social Sciences.

Reynolds, T. (2010) Transnational family relationships, social networks and return migration among British-Caribbean young people. Ethnic and Racial Studies, 33 (5): 797 — 815

Richardson, J. (2006). Self-directed expatriation: family matters. Personnel Review, 35 (4) 46986.

Richardson, J., \& Mallon, M. (2005) Career interrupted? The case of the self-directed expatriate. Journal of World Business, 40, 409-420. 
Roderick, N. (2011) 'Moments of disruption’ and the development of expatriate TESOL teachers. English Australia Journal, 27(1): 18-32.

Ryan, L. (2007) Who do you think you are? Irish nurses encountering ethnicity and constructing identity in Britain. Ethnic and Racial Studies, 30: 416-438.

Selmer, J., \& A. Leung (2007) Symptom and problem focused coping strategies of businesswomen expatriates and their sociocultural adjustments in Hong Kong. Women in Management Review, 22(7): 588-605.

Shaw, W. (2006) Decolonizing geographies of whiteness. Antipode, 38: 851-869.

Stephenson, M., \& Hughes, H (2005) Racialised boundaries in tourism and travel: a case study of the UK black Caribbean community. Leisure Studies, 24(2): 137-160.

Stolley, K (2005) The basic of Sociology. London: Greenwood Press.

Subedi, B \& Daza, S. (2008) The possibilities of postcolonial praxis in education. Race Ethnicity and Education, 11(1): 1-10.

Tanner, R (2007) Expatriate Children in South Asia: Internationalism and isolation. In Behera, D. (Ed) Childhoods in South Asia (pp 334- 342). Delhi: Dorling Kindersley.

Thane, C. \& Farstad, E. (2102) Nationality as a segmentation criterion in tourism research: the case of international tourists' expenditures while on trips in Norway. Tourism Economics, 18(1):203-217.

Thorn, K. (2009) The relative importance of motives for international self-initiated mobility. Career Development International, 14(5): 441-464.

van Riemsdijk, M., \& Wang, Q. (2017). (eds.) Rethinking international skilled migration: A place-based and spatial perspective. London \& New York: Routledge

Wang, C., Wong, S. \& V. Zheng (2014) Postcolonial border crossing. Asian Population Studies, 10(1): 75-95

Wang, X \& Kanungo, R. (2004) Nationality, social network and psychological well-being: expatriates in China. The International Journal of Human Resource Management, 15(45): 775-793

Williams, A. \& Hall, M. (2002) 'Tourism, migration, circulation and mobility: The contingencies of times and place'. In C. M. Hall and A. Williams (Eds.), Tourism and migration: New relationships between production and consumption (pp 1-52). Dordrecht: Kluwer Academic Publishers. 
Yee, H. (2001) Macau in transition: from Colony to Autonomous Region. London: Palgrave MacMillan.

Yip, C (2017) Struggles of ethnic Chinese expats in Hong Kong. Ejiinsight, Feb 7, 2017. http://www.ejinsight.com/20170207-struggles-of-ethnic-chinese-expats-in-hong-kong/ $<$ downloaded Nov 23, 2017>.

Young, M. (2007) English in postcolonial Macau: Functions and attitudes. Asian Englishes, 10(1):104-117

Zimmermann, A., Holman, D., \& Sparrow, P. (2003) Unravelling adjustment mechanisms: Adjustment of German Expatriates to Intercultural Interactions, Work, and Living Conditions in the People's Republic of China. International Journal of Cross Cultural Management, 3(1): 45-66. 
Table 1

Profile of Respondents

$$
(\mathrm{n}=1221)
$$

\begin{tabular}{|c|c|}
\hline Variable & $\begin{array}{l}\% \text { unless stated } \\
\text { otherwise }\end{array}$ \\
\hline \multicolumn{2}{|l|}{ Where data collected } \\
\hline Macau & 56.5 \\
\hline Hong Kong & 43.5 \\
\hline \multicolumn{2}{|l|}{ Age } \\
\hline $18-24$ & 3.3 \\
\hline $25-34$ & 24.5 \\
\hline $35-44$ & 35.8 \\
\hline $45-54$ & 23.6 \\
\hline 55 and above & 12.8 \\
\hline \multicolumn{2}{|l|}{ Gender } \\
\hline Male & 52.5 \\
\hline Female & 47.5 \\
\hline \multicolumn{2}{|l|}{ Partnership status } \\
\hline Partnered & 77.1 \\
\hline Single & 22.9 \\
\hline \% with children & 44.2 \\
\hline \multicolumn{2}{|l|}{ Household income } \\
\hline$<$ US\$65,000 & 17.9 \\
\hline US $\$ 65,000$ to $<$ US $\$ 130,000$ & 27.6 \\
\hline US\$ 130,000 to $<$ US\$ 260,000 & 29.7 \\
\hline US $\$ 260,000$ to $<$ US\$ 390,000 & 16.4 \\
\hline US $\$ 390,000$ or more & 8.5 \\
\hline Vacation leave (median days) & 25 days \\
\hline \multicolumn{2}{|l|}{ Why moved to Hong Kong / Macau } \\
\hline Posted by overseas company & 20.0 \\
\hline Recruited in response to advertisement & 26.2 \\
\hline Sought work here on my own & 25.3 \\
\hline Trailing spouse/partner/family reasons & 23.0 \\
\hline Other business reasons & 5.5 \\
\hline
\end{tabular}




\begin{tabular}{|c|c|}
\hline Variable & $\begin{array}{l}\% \text { unless stated } \\
\text { otherwise }\end{array}$ \\
\hline \multicolumn{2}{|l|}{ Did the chance to travel play any role in the migration decision? } \\
\hline Played no role & 23.7 \\
\hline Played some role & 56.8 \\
\hline A very important reason / most important treason to move & 19.5 \\
\hline \multicolumn{2}{|l|}{ How Long in Hong Kong or Macau (years) } \\
\hline Mean & 11.3 years \\
\hline Median & 8.0 years \\
\hline \multicolumn{2}{|l|}{ Years in Hong Kong/Macau (grouped) } \\
\hline 0 to 3 years & 27.2 \\
\hline 4 to 7 years & 20.6 \\
\hline 8 to 15 years & 21.7 \\
\hline more than 15 years & 30.6 \\
\hline \multicolumn{2}{|l|}{ Intended future stay before leaving } \\
\hline 1 year or less & 13.6 \\
\hline 2 or 3 years & 11.3 \\
\hline 4 or more - stated number & 8.8 \\
\hline open-ended & 66.4 \\
\hline \multicolumn{2}{|l|}{ Does Hong Kong or Macau feel like home? } \\
\hline Somewhat or definitely & 70.3 \\
\hline $\begin{array}{l}\text { Not yet, but hopefully someday / not yet, but it is feeling less like a } \\
\text { foreign place the longer I stay }\end{array}$ & 24.4 \\
\hline Definitely not & 5.3 \\
\hline
\end{tabular}


Table 2

Travel Propensity and Intensity

\begin{tabular}{ll}
\hline Variable & Value \\
\hline Share of respondents who travelled & $91.5 \%$ \\
All trips (among those who travelled) & \\
Mean total number of trips taken & 3.4 \\
Short haul travel (among those who travelled within Asia) & \\
$n$ who travelled short haul & 985 \\
Share of total sample & $88.0 \%$ \\
Mean number of short haul trips & 2.5 \\
Long haul travel (among those who travelled outside of Asia) & \\
$n$ who travelled long & 750 \\
Share of total sample & $67.0 \%$ \\
Mean number of long haul trips (of those who travelled long haul) & 1.7 \\
Duration & \\
Long duration trips (2 weeks or more) & $53.7 \%$ \\
Medium duration trips (7 to 13 nights) & $65.7 \%$ \\
Short duration trips (1 to 6 nights) & $61.3 \%$ \\
\hline
\end{tabular}




\section{Figure 1}

Outbound Travel by Hong Kong Residents Over Time

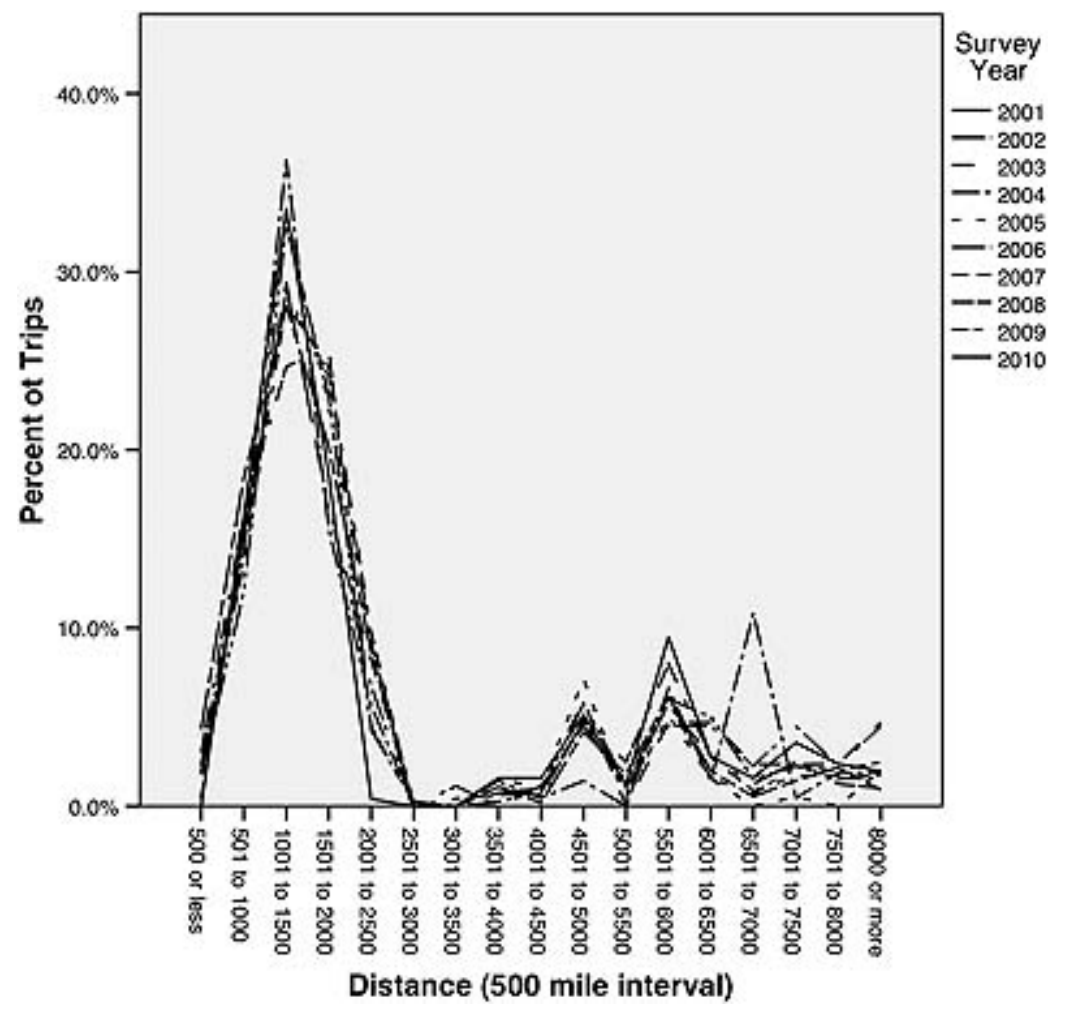

Source: Lee, Denizci-Guillet, Law \& Leung (2012) 
Figure 2

Destination Choice by Distance

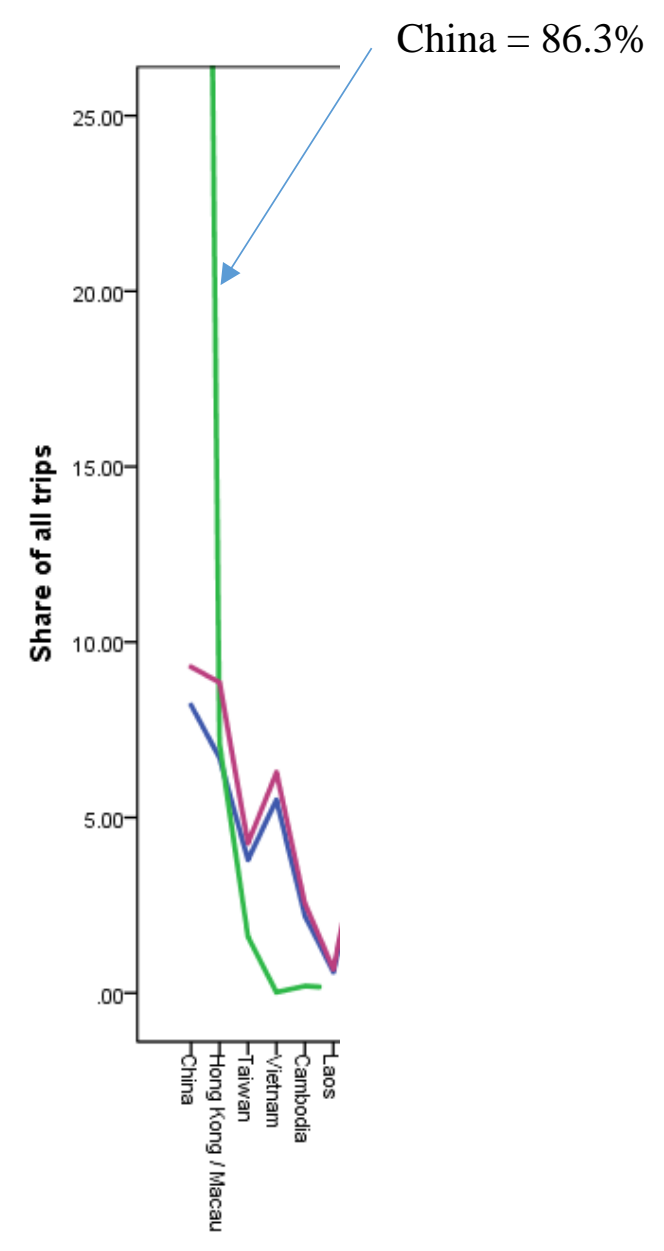

Source: Hong Kong figures - UNWTO 2016 
Figure 3

Travel Patterns by Region of Origin

(excluding travel to their home regions)

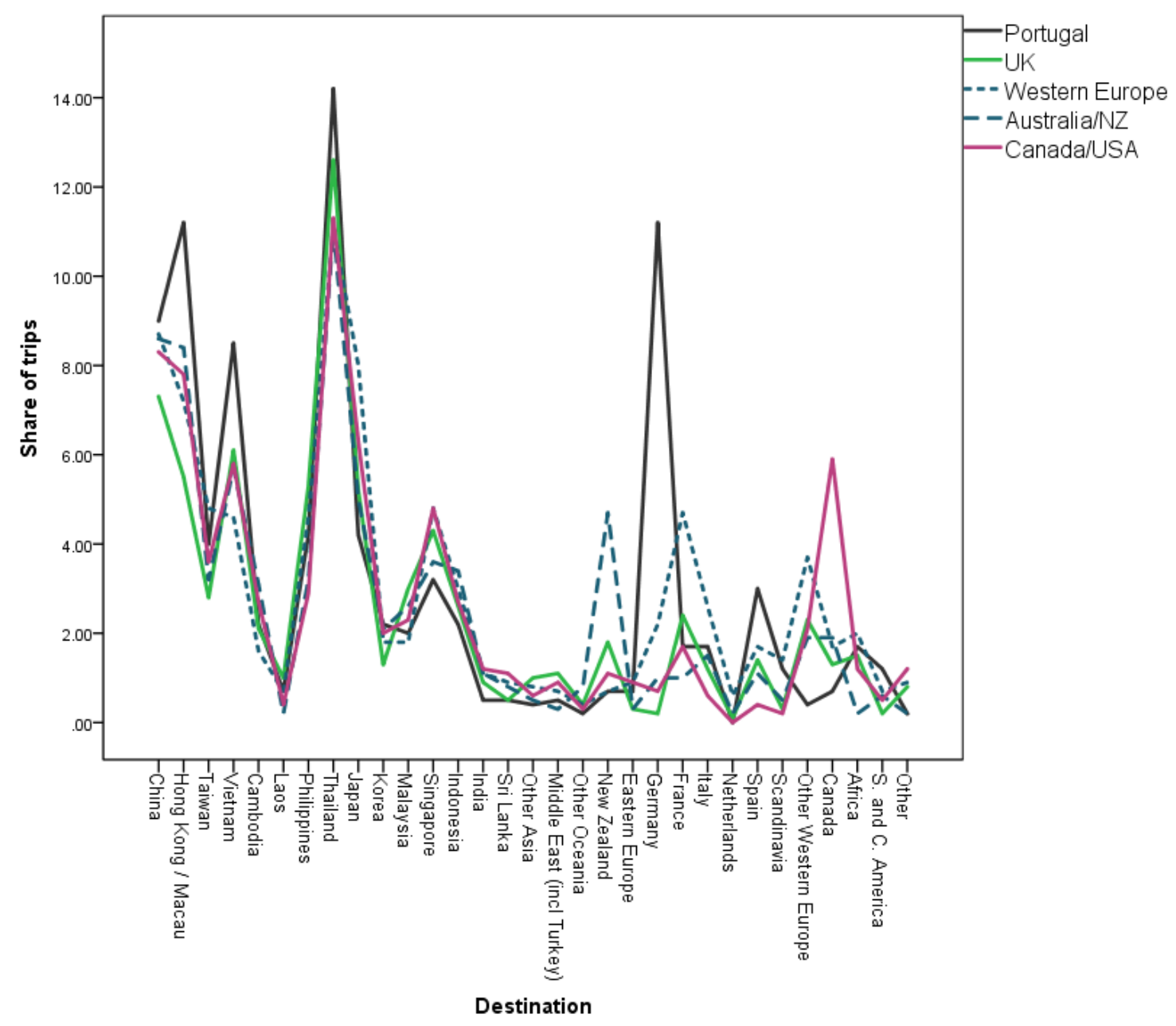

